\title{
Combined therapy with L-Thyroxine and L-Triiodothyronine compared to L-Thyroxine alone in the treatment of primary hypothyroidism
}

\author{
Valentine V. Fadeyev, Tatyana B. Morgunova, Galina A. Melnichenko, Ivan I. Dedov \\ Department of Endocrinology, Moscow Medical Academy, Moscow, Russia
}

\begin{abstract}
OBJECTIVE: The objective of this study was to compare various parameters in patients with hypothyroidism receiving either monotherapy with L-Thyroxine (L-T4) or combination therapy with L-T4 and L-Triiodothyronine (L-T3). DESIGN: We conducted a randomized, controlled trial in 36 premenopausal women with hypothyroidism. The patients were divided into two groups: Group A $(n=20)$ received only $L-T 4$, while Group B received the combination $L-T 4$ and L-T3. The treatment period lasted for 6 months. RESULTS: At baseline, the various parameters examined did not differ in the two groups. No significant difference between monotherapy and combined therapy was demonstrated on TSH level, ECG monitoring, densitometry, or thyroid symptoms score. The lipid profile was better during combined treatment compared to L-T4 alone; in Group A during treatment with L-T4 the levels of cholesterol and Low Density Lipoprotein (LDL) Cholesterol were unchanged, while in group B total cholesterol and LDL decreased $(p<0.05)$. The changes in osteocalcin levels did not differ in the two groups, whereas the levels of urine deoxypyridinoline at the end of therapy were higher in the group with combination therapy, compared to monotherapy. CONCLUSION: Compared with L-T4 alone, replacement therapy with the combination of $\mathrm{L}-\mathrm{T} 4+\mathrm{L}-\mathrm{T3}$ shows favourable changes in serum lipid profile, but higher activation of bone resorption.
\end{abstract}

Key words: Hypothyroidism, Levothyroxine, Thyroid, Triiodothyronine

\section{INTRODUCTION}

Primary hypothyroidism is one of the most common endocrine disorders. Replacement therapy with

\footnotetext{
Address for correspondence:

Tatyana Morgunova, MD, Moscow Medical Academy, Department of Endocrinology, 8 M. Trubezkaja, str. 2, Moscow, Russia 119992, Tel: +74992483888,

Fax: +74992486477, e-mail: tanmorgun@mail.ru

Received 08-11-09, Revised 10-04-10, Accepted 10-05-10
}

thyroid hormones is indicated in all forms of overt hypothyroidism. The first available thyroid hormone preparations were derived from dried animal thyroid glands that contained varying amounts of thyroxine (L-T4) and triiodothyronine (L-T3). ${ }^{1}$ Levothyroxine has become the treatment of choice for correction of hypothyroidism because it has a long half-life and it is converted to $\mathrm{T} 3$ in the peripheral tissues, thus providing stable quantities of T3. ${ }^{2}$ Recent studies have 
revived interest in the combination of L-T4 and L-T3. A number of published studies furnish evidence of favourable changes in the psychological indicators of the combined therapy L-T4+L-T3 compared to monotherapy with L-T4. ${ }^{3,4}$ Other researchers, however, do not confirm the advantages of the combined therapy compared to monotherapy. ${ }^{1-9}$ The objective of this study was to compare various parameters in patients with hypothyroidism receiving either monotherapy with L-T4 or combination therapy with L-T4 and L-T3.

\section{MATERIALS AND METHODS}

\section{Patients}

We conducted a randomized controlled study in 36 premenopausal women with untreated overt primary hypothyroidism (reduced T4 concentration accompanied by increased TSH concentration at the time of initial diagnosis). The patients were divided into two groups: patients in Group A $(n=20)$ received L-T4 at the dose of $1.6 \mu \mathrm{g}$ per $\mathrm{kg}$, while in Group B $(\mathrm{n}=16)$ patients received the combination of L-T4+L-T3. In the combination therapy the calculated dose of L-T4 was reduced by $25 \mu \mathrm{g}$ and replaced by $12.5 \mu \mathrm{g}$ of L-T3 (Table 1). We used block randomization (applying a table of random). The treatment period lasted for 6 months. Patients were examined at baseline and at the end of the treatment period. Assessment was carried out after overnight fasting and before taking the thyroid preparation. The clinical characteristics of the patients at baseline are summarized in Table 1.

Table 1. Baseline clinical characteristics of the patients [Median $\left.\left(25^{\text {th }} ; 5^{\text {th }}\right)\right]$

\begin{tabular}{lccc}
\hline & $\begin{array}{c}\text { Group A } \\
(\mathbf{L - T 4})\end{array}$ & $\begin{array}{c}\text { Group B } \\
(\mathbf{L - T 4 + L - T 3})\end{array}$ & $\begin{array}{c}\text { P* } \\
\text { Value }\end{array}$ \\
\hline $\mathrm{N}$ & 20 & 16 & \\
Age $(\mathrm{yrs})$ & $43[34 ; 46]$ & $40[32 ; 44]$ & 0.43 \\
Body mass index & $26.8[23.0 ; 28.7]$ & $24.6[22.0 ; 27.3]$ & 0.36 \\
$\left(\mathrm{~kg} / \mathrm{m}^{2}\right)$ & & & \\
$\begin{array}{l}\text { Serum TSH (mU/l) } \\
\text { Serum free T4 }\end{array}$ & $44.6[11.8 ; 70.7]$ & $50[9.6 ; 76]$ & 0.724 \\
$($ pmol/l) & $7.8[5.0 ; 10.8]$ & $8.7[5.5 ; 10.1]$ & 0.94 \\
$\begin{array}{l}\text { Serum free T3 } \\
(\mathrm{pmol} / \mathrm{l})\end{array}$ & $2.7[1.95 ; 2.8]$ & $3.2[1.4 ; 3.6]$ & 0.92 \\
\hline
\end{tabular}

*Mann-Whitney criterion was used to examine differences in the median values between the two groups
Blood samples were obtained to determine serum $\mathrm{TSH}$, free T4, free T3, lipid profile, and osteocalcin. Urine samples were collected to determine urinary deoxypyridinoline and creatinine. 24-hour ECGmonitoring and osteodensitometry were also carried out at baseline and at the end of a 6-month period.

Exclusion criteria were the following: peri- and postmenopause, pregnancy, obesity (BMI $>30 \mathrm{~kg} /$ $\mathrm{m}^{2}$ ), major comorbidity, and use of drugs that affect metabolism or bioavailability of thyroid hormones preparations. The study was approved by the Institutional Ethics Committee and subjects gave informed consent.

\section{Methods}

Serum TSH (reference range: $0.4-4 \mathrm{mU} / \mathrm{l}$ ), fT4 (reference range: $11.5-23.2 \mathrm{pmol} / \mathrm{l}$ ) and fT3 (reference range: $3.2-7.2 \mathrm{pmol} / \mathrm{l}$ ) were measured by an immunochemiluminescence method ("Immulite", Diagnostic Products Corporation, Los Angeles, USA). Blood samples were collected in the morning before the thyroid preparation was taken. Osteocalcin (reference range: $3.1-13.3 \mathrm{ng} / \mathrm{ml}$ ) and deoxypyridinoline (reference range: $3.0-7.4 \mathrm{nM} / \mathrm{mM}$ creatinine) were measured by an immunochemiluminescence method. Total cholesterol (normal range: 3.1 - $5.2 \mathrm{mmol} / \mathrm{L}$ ), triglycerides (TG) (normal range: $0.5-2.0 \mathrm{mmol} / \mathrm{L}$ ), high density lipoprotein cholesterol (HDL) (normal range: $0.9-1.9 \mathrm{mmol} / \mathrm{L}$ ), and very low density lipoprotein cholesterol (VLDL) (normal range: $0.2-1.0$ $\mathrm{mmol} / \mathrm{L}$ ) were determined using the commercial set "Vital-Diagnostic" (St. Petersburg, Russia) on an "Eos-bravo" autoanalyzer (Hospitex Diagnostics, Italy). LDL cholesterol was calculated according to the equation: low density lipoproteins cholesterol (LDL) $=$ total cholesterol $-\mathrm{HDL}-$ triglycerides $/ 2.2$.

24-hour ECG monitoring and analysis was performed using a 2-channels SCHILLER MT-100 ECGdevice and an MT-200 operating system (Schiller AG, Switzerland). Bone mass measurement was conducted at forearm using dual energy X-ray bone densitometer "DTX-200" (“Osteometer").

Symptoms of hypothyroidism were assessed using the 4-point scale, ranging from 0 to 3 . In the scale, twelve of the most common symptoms of hypothyroidism were included. At the final visit patients were 
asked which treatment they preferred.

\section{Statistical analysis}

Statistical analysis was performed using the STATISTICA 6.0 software program (Stat-Soft, 2001) and a "Primer of BIOSTATISTICS" 4.03 (S.A. Glantz, McGraw Hill, 1998). To compare independent samples, the Mann-Whitney criterion was used. Wilcoxon's test $(\mathrm{W})$ was employed to compare related samples. The $\chi^{2}$-test was performed to compare categorical variables. The Kruskal-Wallis test was used to compare more than two independent samples. Numerical data in the text and in the tables are presented as Me $[25 ; 75]\left(\mathrm{Me}=\right.$ median; 25 and $75=1^{\text {st }}$ and $3^{\text {rd }}$ quartiles). A $p$-value of less than 0.05 was regarded as statistically significant.

\section{RESULTS}

\section{Clinical findings}

The clinical characteristics of the patients at baseline did not differ in the two groups (Table 1).

\section{Biochemistry results}

At baseline, serum TSH values were above the upper limit of the normal range in all 36 patients and there was no difference between Groups A and B (Table 2). At six months, no significant difference between treatments was detected with regard to TSH levels.

\section{Lipoprotein profiles}

At baseline, total cholesterol was above the upper limit of the normal range ( $>5.2 \mathrm{mmol} /$ liter $)$ in 23 of 36 patients $(66 \%)$, while LDL cholesterol was above

Table 2. TSH at baseline and at the end of treatment, Median $\left(25^{\text {th }} ; 75^{\text {th }}\right)$, in $\mathrm{mU} / 1$

\begin{tabular}{|c|c|c|c|}
\hline Groups & Baseline & $\begin{array}{c}\text { After } \\
6 \text { months } \\
\text { of treatment }\end{array}$ & W, p value \\
\hline Group A (L-T4) & $44.6[11.8 ; 70.7]$ & $2.4[1.2 ; 3.7]$ & $<0.05$ \\
\hline $\begin{array}{l}\text { Group B } \\
\text { (L-T4+L-T3) }\end{array}$ & $50[9.6 ; 76]$ & $1.9[0.8 ; 3.1]$ & $<0.05$ \\
\hline $\begin{array}{l}\text { Mann-Whitney } \\
\text { criterion, p value }\end{array}$ & 0.724 & 0.524 & \\
\hline
\end{tabular}

W: Wilcoxon test the normal range in 22 of 36 patients $(61 \%)$ and triglycerides in 2 of 36 women (6\%).

The baseline lipoprotein profiles in the two groups were comparable. However, the changes in total cholesterol during the study period were different in the two groups (Table 3, Figure 1) In the patients of group A, the total cholesterol did not significantly change compared to baseline (Figure 1), while in Group B, the level of serum cholesterol decreased significantly and was lower compared to Group A at the end of treatment. Analogous changes were disclosed with regard to LDL cholesterol levels (Table 3). No significant difference between monotherapy and combined therapy was observed in TG and HDL levels.

\section{Holter ECG monitoring}

Holter ECG monitoring was conducted in each patient at baseline and at the end of the 6 months' treatment. There was no significant difference between monotherapy and combined therapy on the minimum, maximum, and mean heart rate. Also, the mean heart rate analyzed 2 hours after the administration of thyroid hormone preparations did not differ between monotherapy and combined therapy (Table 4).

\section{Bone metabolism}

There was no significant difference between treatments in serum osteocalcin. Nevertheless, in Group B

Table 3. Total cholesterol and LDL cholesterol at baseline and at the end of treatment, Median $\left(25^{\text {th }} ; 75^{\text {th }}\right), \mathrm{mmol} / \mathrm{l}$

\begin{tabular}{|c|c|c|c|}
\hline Groups & Baseline & $\begin{array}{c}\text { After } \\
6 \text { months } \\
\text { of treatment }\end{array}$ & $\mathbf{W}, \mathbf{p}$ value \\
\hline \multicolumn{4}{|l|}{ Total cholesterol } \\
\hline Group A (L-T4) & $5.4[4.6 ; 6.9]$ & $5.7[4.5 ; 5.9]$ & $>0.05$ \\
\hline $\begin{array}{l}\text { Group B } \\
(\mathrm{L}-\mathrm{T} 4+\mathrm{L}-\mathrm{T} 3)\end{array}$ & $6.1[5.4 ; 7.2]$ & $4.6[3.4 ; 4.7]$ & $<0.05$ \\
\hline $\begin{array}{l}\text { Mann-Whitney } \\
\text { criterion, p value }\end{array}$ & $>0.05$ & $<0.05$ & \\
\hline \multicolumn{4}{|l|}{ LDL cholesterol } \\
\hline Group A (L-T4) & $3.9[2.9 ; 5.1]$ & $3.5[2.8 ; 4.0]$ & $>0.05$ \\
\hline $\begin{array}{l}\text { Group B } \\
(\mathrm{L}-\mathrm{T} 4+\mathrm{L}-\mathrm{T} 3)\end{array}$ & $4.2[3.6 ; 4.5]$ & $2.7[1.9 ; 3.2]$ & $<0.05$ \\
\hline $\begin{array}{l}\text { Mann-Whitney } \\
\text { criterion, p value }\end{array}$ & $>0.05$ & $<0.05$ & \\
\hline
\end{tabular}

W: Wilcoxon test 

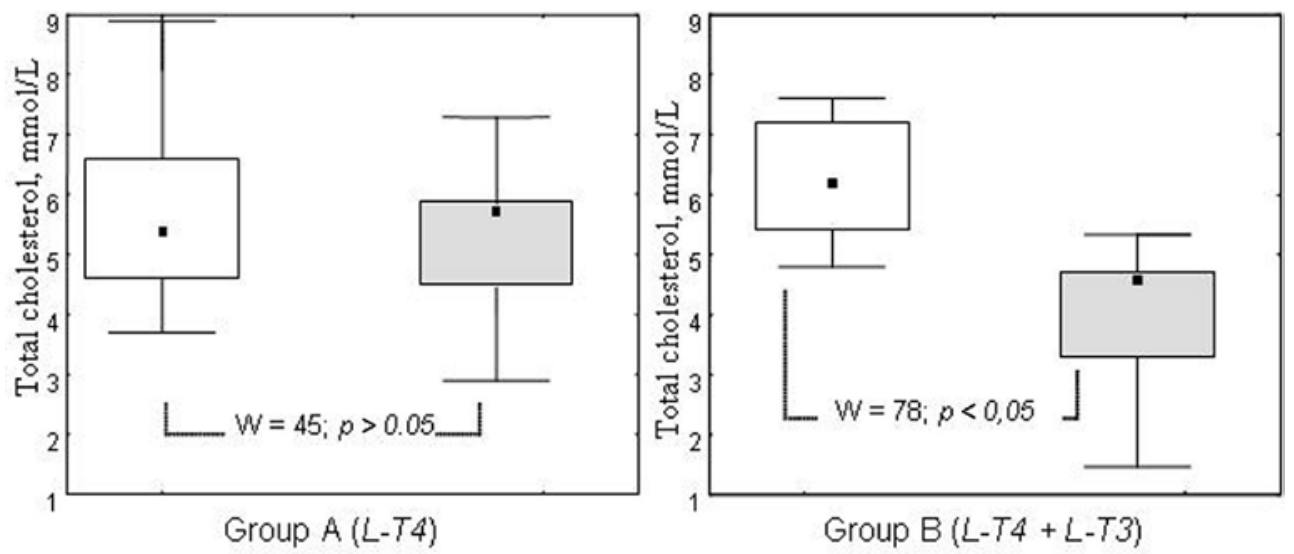

At baseline (decompensated hypothyroidism)

At the end of treatment

Figure 1. Total cholesterol at the end of treatment, Median $\left(25^{\text {th }} ; 75^{\text {th }}\right) \mathrm{mmol} / \mathrm{L}$.

Table 4. Mean heart rate at baseline and at the end of treatment and heart rate 2 hours after taking the thyroid hormones preparation, Median $\left(25^{\text {th }} ; 75^{\text {th }}\right)$, beats $/$ min

\begin{tabular}{|c|c|c|c|}
\hline \multicolumn{4}{|c|}{ Mean heart rate at the end of treatment } \\
\hline Groups & Baseline & $\begin{array}{c}\text { After } \\
6 \text { months } \\
\text { of treatment }\end{array}$ & $W$, p value \\
\hline Group A (L-T4) & $78[75 ; 82]$ & $81[76 ; 82]$ & $>0.05$ \\
\hline Group B (L-T4+L-T3) & $77[72 ; 79]$ & $79[77 ; 82]$ & $>0.05$ \\
\hline $\begin{array}{l}\text { Mann-Whitney } \\
\text { criterion, p value }\end{array}$ & $>0.05$ & $>0.05$ & \\
\hline \multicolumn{4}{|c|}{ Heart rate 2 hours after taking thyroid hormones preparations } \\
\hline Groups & & $\begin{array}{l}\text { At the end of th } \\
\text { treatment peric }\end{array}$ & \\
\hline Group A (L-T4) & & $86.5[84.5 ; 93.5$ & \\
\hline Group B (L-T4+L-T3) & & $86.5[84.5 ; 90.8$ & \\
\hline $\begin{array}{l}\text { Mann-Whitney } \\
\text { criterion, p value }\end{array}$ & & $>0.05$ & \\
\hline
\end{tabular}

W: Wilcoxon test

serum osteocalcin increased by $3.35[0.18 ; 8.8] \mathrm{ng} / \mathrm{ml}$, whereas in Group A it increased by only $0.4[-0.5 ; 3.9]$ $\mathrm{ng} / \mathrm{ml}$ (Table 5). The changes were not significantly different $(\mathrm{T}=208.0$; $\mathrm{p}>0.05)$. The urine deoxypyridinoline in group $\mathrm{B}$ significantly increased after combined therapy and was higher than in group $\mathrm{A}$ at the end of therapy $(p<0.05)$ (Figure 2). No significant difference between monotherapy with L-T4 and combined therapy was revealed in densitometry.

\section{Preference of treatment}

At the final visit patients were asked which treatment they preferred. Of 36 study patients, 10 preferred L-T4+L-T3 treatment (27.8\%), 8 preferred L-T4 treatment (22.2\%), and 18 patients $(50 \%)$ had no preference.

\section{DISCUSSION}

In a previous study ${ }^{10}$ we compared the effect of L-T4 versus combination L-T4 + L-T3 therapy on the serum thyroid hormone levels. We found that L-T4 monotherapy was associated with non-physiologically high FT4 and low FT3 levels, while TSH values did not differ in the two groups.

In the present study we conducted a randomized controlled trial of non-blinded design in 36 hypothyroid premenopausal women without previous therapy in order to assess possible differential influence of the two therapeutic regimens (L-T4 versus combined L-T4, L-T3) on clinical features, lipid profile, bone metabolism markers, bone density, and 24-hour electrocardiographic recording.

\section{Lipoprotein profiles}

Elevated levels of total cholesterol, LDL cholesterol, and apolipoprotein B are well documented features of overt hypothyroidism. ${ }^{11}$ These changes are reversible upon treatment. 

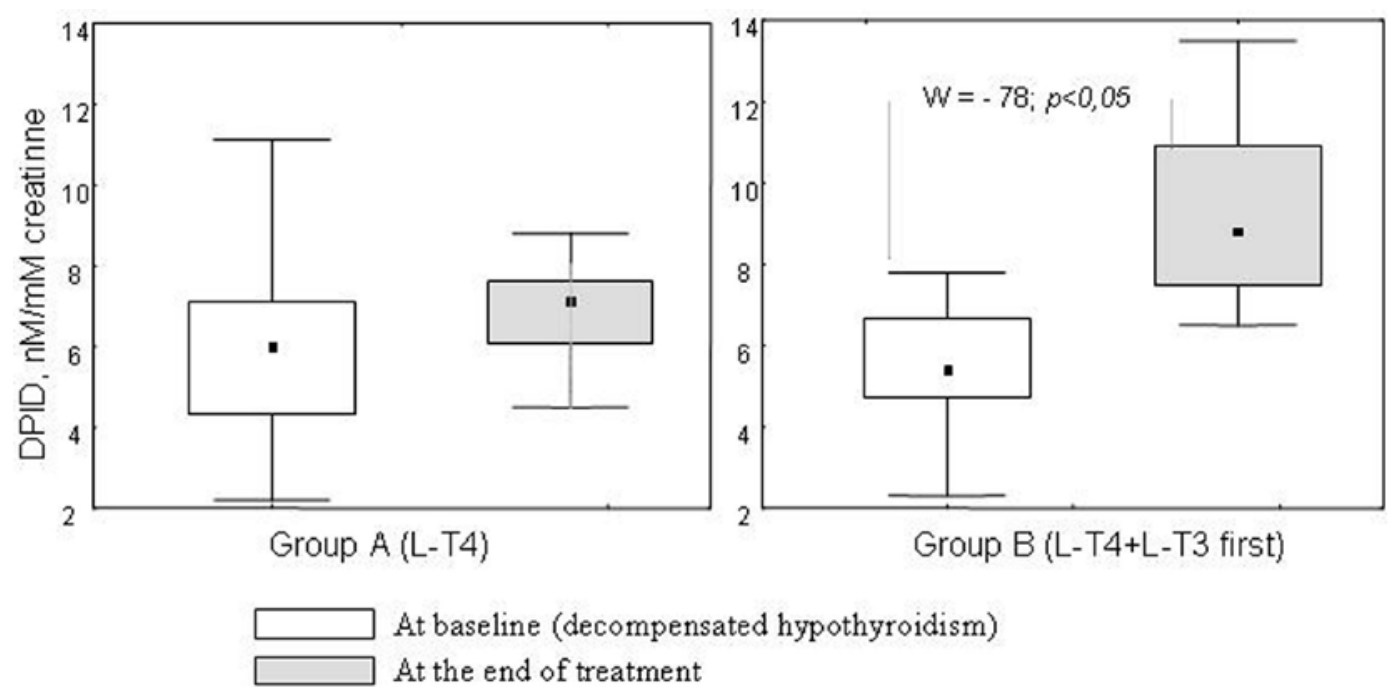

Figure 2. Deoxypyridinoline (DPID) creatinine ratio $(\mathrm{nM} / \mathrm{mM})$ at the end of treatment, Median $\left(25^{\text {th }} ; 75^{\text {th }}\right)$.

In estimating the dynamics of the lipid profile parameters with the two therapeutic regimens, a favourable effect of combined therapy on serum lipids was observed. Thus, in group B, 6 months after the combination therapy the level of total cholesterol decreased substantially and was significantly lower than the corresponding level in group A (1-T4 monotherapy). Analogous changes were seen in LDL values.

Other authors have reported no significant differences in total cholesterol and lipoproteins between monotherapy with L-T4 and the combination of L-T4+L-T3. ${ }^{1,3,12}$ The changes detected in lipoprotein profiles in our study could be explained by the homogeneity of our groups; our study included 36 premenopausal women without any concomitant disease, while other studies were conducted in groups comprised of both men and women, the women being of reproductive age or peri- and postmenopause.

\section{Holter ECG monitoring}

The hemodynamic changes typical for hypothyroidism are opposite to those for hyperthyroidism. The most common signs are bradycardia, mild hypertension, and a narrowed pulse pressure. ${ }^{13}$ It has been demonstrated that replacement therapy with thyroid hormones reverses all the cardiovascular changes associated with hypothyroidism. ${ }^{13-15}$ We looked for possible negative influence of the combination L-T4 + L-T3 on the cardiovascular system by Holter ECG monitoring.
There was no significant difference between the two therapeutic regimens in the parameters examined (Table 4). It is well known that liothyronine reaches peak levels 2 to 4 hours after oral administration. In this connection, the mean heart rate was also analyzed 2 hours after the administration of thyroid hormone preparations. There was no significant difference in this parameter between monotherapy and combined therapy. Thus, the replacement dose of L-T3 did not adversely affect the cardiovascular system.

\section{Bone metabolism}

The relation between thyroid hormone and bone is well known and was first recognized in the 1890s when von Recklinghausen reported a patient with hyperthyroidism and multiple fractures. Hyperthyroidism (both exogenous and endogenous) accelerates bone turnover and shortens the normal bone remodeling cycle. Thyroid hormones seem to be more detrimental for cortical bone (found in the hip and forearm) than for trabecular bone (found in the spine). ${ }^{16}$

There was no difference between treatments in serum osteocalcin. Nevertheless, during combined treatment serum osteocalcin increased by $3.35 \mathrm{ng} / \mathrm{ml}$, whereas during monotherapy it increased by $0.4 \mathrm{ng} / \mathrm{ml}$ (Table 5). In analyzing the dynamics of this parameter it was shown that against a background of the combined therapy a slightly greater stimulation of bone formation took place compared to monotherapy 
with L-T4, which did not reach statistical significance $(\mathrm{p}>0.05)$.

However, there was a significant difference in the level of deoxypyridinoline between treatments $(p<0.05)$. In the group of patients who received combined therapy, deoxypyridinoline significantly increased $(\mathrm{p}<0.05)$, while no difference was observed in deoxypyridinoline after monotherapy. The difference between the groups after the 6 months' therapy was significant $\mathrm{p}<0.05$ (Table 5, Figure 2). Densitometry demonstrated no significant difference between monotherapy and combined therapy. The absence of a statistically significant change of bone mineral density in our study could be explained by the relatively short duration of the study period.

We can conclude that against a background of the combined L-T4+L-T3 therapy, a slightly greater activation of bone resorption took place in comparison with monotherapy. It is well known that liothyronine reaches peak levels 2 to 4 hours after oral administration, which may lead to increased levels of $\mathrm{T} 3$ at that period of time. Over the past few years efforts have been made to produce LT3 preparations which are slowly absorbed, time-released formulation. ${ }^{17}$ The application of such a preparation was recently reported by Hennemann at al. ${ }^{18}$ The authors demonstrated that

Table 5. Changes in serum osteocalcin (ng/ml) and deoxypyridinoline/creatinine ratio $(\mathrm{nM} / \mathrm{mM})$ at the end of the treatment period, Median $\left(25^{\text {th }} ; 75^{\text {th }}\right), \mathrm{ng} / \mathrm{ml}$

\begin{tabular}{|c|c|c|c|}
\hline \multicolumn{2}{|l|}{ Groups } & \multicolumn{2}{|c|}{$\begin{array}{l}\text { After } 6 \text { months } \\
\text { of treatment }\end{array}$} \\
\hline \multicolumn{4}{|c|}{ Changes in serum osteocalcin at the end of treatment $(\mathrm{ng} / \mathrm{ml})$} \\
\hline \multicolumn{2}{|l|}{$\overline{\text { Group A (L-T4) }}$} & \multicolumn{2}{|c|}{$0.4[-0.5 ; 3.9]$} \\
\hline \multicolumn{2}{|l|}{ Group B (L-T4+L-T3) } & \multicolumn{2}{|c|}{$3.35[0.18 ; 8.8]$} \\
\hline \multicolumn{2}{|c|}{ Mann-Whitney criterion, $p$ value } & \multicolumn{2}{|l|}{$>0.05$} \\
\hline \multicolumn{4}{|c|}{$\begin{array}{l}\text { Deoxypyridinoline/creatinine ratio at the end of treatment (nM } \\
\text { mM) }\end{array}$} \\
\hline Groups & Baseline & $\begin{array}{c}\text { After } \\
6 \text { months } \\
\text { of treatment }\end{array}$ & $\begin{array}{l}\mathrm{W}, \mathbf{p} \\
\text { value }\end{array}$ \\
\hline Group A (L-T4) & $6.0[4.1 ; 7.5]$ & $7.1[6.1 ; 7.6]$ & $>0.05$ \\
\hline Group B (L-T4+L-T3) & $5.2[3.8 ; 6.3]$ & $8.8[7.5 ; 10.8]$ & $<0.05$ \\
\hline $\begin{array}{l}\text { Mann-Whitney } \\
\text { criterion, p value }\end{array}$ & $>0.05$ & $<0.05$ & \\
\hline
\end{tabular}

W: Wilcoxon test the use of a new, slow-release formulation of LT3, at a low dose, combined with LT4 in treating hypothyroid subjects led to considerable increase of serum $\mathrm{T} 4$ and T3 levels and improvement of the T4/T3 ratio and serum TSH as compared to monotherapy. ${ }^{18}$ They could not detect peak of T3 in contrast to administration of plain T3. The introduction of a slow-release compound of this nature promises to enrich the arsenal of thyroid hormone preparations. ${ }^{17}$

Furthermore, another important aspect in the comparison of these two variants of therapy can be the fact of preference by a patient of one of the two types of treatment. At the final visit the patients were asked which treatment they preferred. Of the 36 patients completing the study, 10 preferred the L-T4+L-T3 regimen $(27.8 \%)$ and 8 preferred L-T4 $(22.2 \%)$. It is an interesting fact that $50 \%$ of the patients (18 from 36) had no preference.

Whereas the majority of hypothyroid patients are satisfied with T4 replacement therapy, some are not. How can we explain the dissatisfaction? The first explanation is nonspecific in nature. It could be that simply being aware of having a chronic disease requiring lifelong treatment and regular control visits makes the patients feel unhappy and less healthy. The second explanation may specifically be related to the way in which we replace the deficit in thyroid hormone with only $\mathrm{T}_{4}$, failing to mimic precisely the thyroidal secretion rates of $T_{4}$ and $T_{3}$, and the serum concentrations of free $T_{4}$ and free $T_{3}$ found in healthy subjects. ${ }^{19}$

According to some authors, patients usually preferred the combination of L-T4+L-T33,20-22. In the study of Escobar-Morreale H.F. et al, of the 26 patients, 18 (69\%) preferred the combination of L-T4+L-T3. ${ }^{20}$ Nygaard B et al found that $49 \%$ of patients preferred the combination and $15 \%$ the monotherapy $(p=0.002) .{ }^{21}$ Analogous data were found in a large study conducted by Appelhof et al. ${ }^{22}$ In this study, 141 patients were randomized to receive either monotherapy with L$\mathrm{T} 4$, or the combination of L-T4+L-T3 at a ratio of 10:1 and 5:1. The study medication was preferred to usual treatment by $29.2 \%, 41.3 \%$, and $52.2 \%$ in the L-T4, 10:1 ratio, and 5:1 ratio groups, respectively. Although patients preferred combined L-T4+L-T3 therapy to usual L-T4 therapy, changes in mood, 
fatigue, well-being, and neurocognitive functions could not satisfactorily explain the preference of L$\mathrm{T} 4+\mathrm{L}-\mathrm{T} 3$ combination therapy. It is interesting that decrease in weight was correlated with increased satisfaction with study medication. In the EscobarMorreale H.F. et al study ${ }^{20}$ only a minimal reduction in body weight was found (mean loss of $0.5 \mathrm{~kg}$ and 1.7 $\mathrm{kg}$ in 15 weeks with the 10:1 and 5:1 combinations, respectively). In our study we also found only minimal, statistically non-significant reduction in body weight in both groups.

\section{CONCLUSION}

Compared with L-T4 alone, replacement treatment with combination of L-T4+L-T3 shows improvement in serum lipid profiles, but higher activation of bone resorption. No particular preference for either therapeutic regimen was expressed by the patients.

\section{REFERENCES}

1. Clyde PW, Harari AE, Getka EJ, Shakir KM, 2003 Combined levothyroxine plus liothyronine compared with levothyroxine alone in primary hypothyroidism: a randomized controlled trial. JAMA 290: 2952-2958.

2. Grozinsky-Glasberg S, Fraser A, Nahshoni E, Weizman A, Leibovici L, 2006 Thyroxine-triiodothyronine combination therapy versus thyroxine monotherapy for clinical hypothyroidism: meta-analysis of randomized controlled trials. J Clin Endocrinol Metab 91: 2592-2599.

3. Bunevicius R, Kazanavicius G, Zalinkevicius R, Prange AJ, Jr, 1999 Effects of thyroxine as compared with thyroxine plus triiodothyronine in patients with hypothyroidism. N Engl J Med 340: 424-429.

4. Bunevicius R, Prange AJ, 2000 Mental improvement after replacement therapy with thyroxine plus triiodothyronine: relationship to cause of hypothyroidism. Int $\mathbf{J}$ Neuropsychopharmacol 3: 167-174.

5. Cassio A, Cacciari E, Cicognani A, et al, 2003 Treatment for congenital hypothyroidism: thyroxine alone or thyroxine plus triiodothyronine? Pediatrics 111: 1055-1060.

6. Levitt A, Silverberg J, 2002 T4 plus T3 treatment for hypothyroidism: a double-blind comparison with usual T4. $74^{\text {th }}$ Annual Meeting of the American Thyroid Association, Los Angeles, California, October 10-13.

7. Sawka AM, Gerstein HC, Marriott MJ, MacQueen GM, Gernstein HC, 2003 Does a combination regimen of thyroxine (T4) and 3,5,3'-triiodothyronine improve depressive symptoms better than $\mathrm{T} 4$ alone in patients with hypothyroidism? Results of a double-blind, randomized, controlled trial. J Clin Endo crinol Metab 88:
4551-4555.

8. Siegmund W, Spieker K, Weike AI, et al, 2004 Replacement therapy with levothyroxine plus triiodothyronine (bioavailable molar ratio 14:1) is not superior to thyroxine alone to improve well-being and cognitive performance in hypothyroidism. Clin Endocrinol (Oxf). 60: 750-757.

9. Walsh JP, Shiels L, Lim EM, et al, 2003 Combined thyroxine/liothyronine treatment does not improve wellbeing, quality of life, or cognitive function compared to thyroxine alone: a randomized controlled trial in patients with primary hypothyroidism. J Clin Endocrinol Metab 88: 4543-4550.

10. Fadeyev VV, Morgunova TB, Sytch JP, Melnichenko GA, 2005 TSH and thyroid hormones concentrations in patients with hypothyroidism receiving replacement therapy with L-thyroxine alone or in combination with L-triiodothyronine. Hormones (Athens) 4: 101-107.

11. Cappola AR, Ladenson PW, 2003 Hypothyroidism and Atherosclerosis. J Clin Endocrinol Metab 88: 24382444.

12. Saravanan P, Simmons DJ, Greenwood R, Peters TJ, Dayan CM, 2005 Partial Substitution of Thyroxine $\left(\mathrm{T}_{4}\right)$ with Tri-Iodothyronine in Patients on $\mathrm{T}_{4}$ Replacement Therapy: Results of a Large Community-Based Randomized Controlled Trial. J Clin Endocrinol Metab 90: 805-812.

13. Klein I, Ojamaa K, 2001 Thyroid hormone and the cardiovascular system. N Engl J Med 344: 501-509.

14. Wieshammer S, Keck FS, Waitzinger J, et al, 1989 Acute hypothyroidism slows the rate of left ventricular diastolic relaxation. Can J Physiol Pharmacol 67:1007-1010.

15. Crowley WFJr, Ridgway EC, Bough EW, et al, 1997 Noninvasive evaluation of cardiac function in hypothyroidism: response to gradual thyroxine replacement. $\mathrm{N}$ Engl J Med 296: 1-6.

16. Uzzan B, Campos J, Cucherat M, Nony P, Boissel JP, Perret GY, 1996 Effects on bone mass of long term treatment with thyroid hormones: a meta-analysis. J Clin Endocrinol Metab 81: 4278-4289.

17. Duntas LH, 2005 Reassessment of combined LT4 and LT3 treatment for hypothyroidism: the prospects for slow-release T3 preparations. Hormones (Athens) 4:108-110.

18. Hennemann G, Docter R, Visser TJ, Postema PT, Krenning EP, 2004 Thyroxine plus low-dose, slow-release triiodothyronine replacement in hypothyroidism: Proof of principle. Thyroid 14: 271-275.

19. Wiersinga WM, 2009 Do we need still more trials on $\mathrm{T}_{4}$ and $\mathrm{T}_{3}$ combination therapy in hypothyroidism? Eur J Endocrinol 161: 955-959.

20. Escobar-Morreale HF, Botella-Carretero JI, GomezBueno M, Galán JM, Barrios V, Sancho J, 2005 Thyroid Hormone Replacement Therapy in Primary Hypothyroidism: A Randomized Trial Comparing L-Thyroxine plus Liothyronine with L-Thyroxine Alone. Ann Intern 
Med 142: 412-424.

21. Nygaard B, Jensen EW, Kvetny J, et al, 2009 Effect of combination therapy with thyroxine (T4) and 3,5,3'-triiodothyronine versus T4 monotherapy in patients with hypothyroidism, a double-blind, randomized cross-over study. Eur J Endocrinol 161: 895-902.
22. Appelhof B, Fliers E, Wekking EM, et al, 2005 Combined therapy with levothyroxine and liothyronine in two ratios, compared with levothyroxine monotherapy in primary hypothyroidism: a double-blind, randomized, controlled clinical trial. J Clin Endocrinol Metab 90: 2666-2674. 